\title{
Chloroquine-containing organoruthenium complexes are fast-acting multistage antimalarial agents
}

\author{
TAÍS S. MACEDO ${ }^{1} \dagger$, LEGNA COLINA-VEGAS $^{2} \dagger$, MARCELO DA PAIXÃO $^{1}$, \\ MARIBEL NAVARRO ${ }^{3}$, BRENO C. BARRETO ${ }^{1,4}$, POLIANA C. M. OLIVEIRA $^{1,4}$, \\ SIMONE G. MACAMBIRA ${ }^{4,5}$, MARTA MACHADO ${ }^{6}$, MIGUEL PRUDENCIO ${ }^{6}$, \\ SARAH D'ALESSANDRO ${ }^{7}$, NICOLETTA BASILICO ${ }^{8}$, DIOGO R. M. MOREIRA ${ }^{1}$, \\ ALZIR A. BATISTA ${ }^{2}$ and MILENA B. P. SOARES ${ }^{1,5 *}$ \\ ${ }^{1}$ FIOCRUZ, Centro de Pesquisas Gonçalo Moniz, 40296-710, Salvador, BA, Brazil \\ ${ }^{2}$ Departamento de Quimica, UFSCAR, 13565-905, São Carlos, SP, Brazil \\ ${ }^{3}$ INMETRO, Xerém, 25250-020, Rio de Faneiro, RY, Brazil \\ ${ }^{4}$ Instituto de Ciências da Saúde, Universidade Federal da Bahia, CEP 40110-100, Salvador, BA, Brazil \\ ${ }^{5}$ Centro de Biotecnologia e Terapia Celular, Hospital São Rafael, CEP 41253-190 Salvador, BA, Brazil \\ ${ }^{6}$ Instituto de Medicina Molecular, Faculdade de Medicina, Universidade de Lisboa, 1649-028 Lisboa, Portugal \\ ${ }^{7}$ Dipartimento di Scienze Farmacologiche e Biomolecolari, Università degli Studi di Milano, 20133 Milan, Italy \\ ${ }^{8}$ Dipartimento di Scienze Biomediche, Chirurgiche e Odontoiatriche, Universitá degli Studi di Milano, 20133 Milan, Italy
}

(Received 24 March 2016; revised 13 May 2016; accepted 5 Fune 2016; first published online 21 Fuly 2016)

SUMMARY

We report the pharmacological activity of organoruthenium complexes containing chloroquine (CQ) as a chelating ligand. The complexes displayed intraerythrocytic activity against CQ-sensitive 3D7 and CQ-resistant W2 strains of Plasmodium falciparum, with potency and selectivity indexes similar to those of CQ. Complexes displayed activity against all intraerythrocytic stages, but moderate activity against Plasmodium berghei liver stages. However, unlike CQ, organoruthenium complexes impaired gametocyte viability and exhibited fast parasiticidal activity against trophozoites for $P$. falciparum. This functional property results from the ability of complexes to quickly induce oxidative stress. The parasitaemia of $P$. berghei-infected mice was reduced by treatment with the complex. Our findings demonstrated that using chloroquine for the synthesis of organoruthenium complexes retains potency and selectivity while leading to an increase in the spectrum of action and parasite killing rate relative to CQ.

Key words: Malaria, Plasmodium falciparum, Plasmodium berghei, chloroquine, organoruthenium complexes, oxidative stress.

\section{INTRODUCTION}

Malaria remains a major health problem in the world. The latest survey published by the World Health Organization estimates that $3 \cdot 2$ billion people live in malaria-endemic areas, which accounts for 214 million cases each year and 438000 deaths (WHO, 2015). Malaria is caused by Plasmodium parasites injected into the mammalian host through the bite of an infected female Anopheles mosquito. The life cycle of Plasmodium parasites oscillates between a mammalian host and an invertebrate vector. In the mammalian host, sporozoites injected by an infected mosquito home to the liver, where they undergo an asymptomatic, yet obligatory, phase of development inside hepatocytes (Prudêncio et al. 2006). This results in the formation of thousands of erythrocyte-infectious merozoites that invade red blood cells and cause the symptoms of malaria. The transmission of the human parasite

* Corresponding author: FIOCRUZ, Centro de Pesquisas Gonçalo Moniz, CEP 40296-710, Salvador, BA, Brazil. Phone: (+55)71-31762292. E-mail: milena@bahia.fiocruz.br $\dagger$ These authors share first authorship. to the mosquito is due to the gametocyte sexual form, which, when present in the bloodstream of the human host, can eventually be ingested by the mosquito vector during feeding (Nilsson et al. 2015). While $P$. falciparum is the deadliest humaninfective malaria parasite, there are an additional four species of Plasmodium, Plasmodium vivax, Plasmodium ovale, Plasmodium malariae and Plasmodium knowlesi, capable of causing malaria in humans. Moreover, $P$. vivax and $P$. ovale are capable forming hypnozoites, dormant parasite forms that may lead to disease relapses long after the initial symptomatic infection has been treated.

Chemotherapy has long been a mainstay in the combat against malaria, but increasing emergence of drug resistance is limiting malarial control (Petersen et al. 2011; Price et al. 2014). Another problem regarding current therapies is that most available drugs have a narrow spectrum of action. The front-line antimalarial quinolines chloroquine (CQ), mefloquine and amodiaquine present long half-lives, affordable cost and safety profile, but lack strong activity against sexual and liver parasite forms, which are important stages for interrupting 
transmission and avoiding relapse, respectively (Prudêncio et al. 2015; Stone et al. 2015). Therefore, it is necessary to develop new antimalarial drugs with a multistage spectrum of action.

Compounds containing transition metals (i.e. metal complexes) are considered promising antimalarial agents (Scovill et al. 1982; Gabbiani et al. 2009; Khanye et al. 2010; Glans et al. 2011, 2012a, b; Adams et al. 2013; Barbosa et al. 2014; Chellan et al. 2014; Adams et al. 2015). A substantial number of metal complexes containing $\mathrm{CQ}$ as a ligand have been investigated as antimalarial agents, employing various metals, a variety of ligands and different numbers of chloroquine molecules. An improvement in the potency against intraerythrocytic stages of $P$. falciparum was observed in most cases, in comparison with metalfree CQ. An interesting finding is that the antiparasitic potency is not superior to complexes containing two CQ molecules in the structure, which indicates that metal complexes are not mere drug delivery systems that act by releasing $\mathrm{CQ}$ and that, instead, the entire chemical structure is involved in the antiparasitic activity (Sánchez-Delgado et al. 1996; Goldberg et al. 1997; Lewis et al. 1997; Navarro et al. 1997, 2004, 2011a, b, 2014; Rajapakse et al. 2009). Given this promising outlook, CQ analogs have been employed in the metal complex composition in the last years and given rise to many successful outcomes (Dubar et al. 2011, 2013; Glans et al. 2012a, b; Salas et al. 2013; Ekengard et al. 2015). Investigations of the mechanism of action demonstrated that CQ-metal complexes display different interactions with $\beta$-hematin, optimal oil-aqueous partition permeability and fast accumulation in the parasitic vacuoles (Martínez et al. 2009, 2011; Navarro et al. 2011a, b). Furthermore, it has been shown that the antimalarial activity of ferroquine, a CQ-derived iron organometallic compound, is superior to that of $\mathrm{CQ}$, due to its ability to produce reactive oxygen species (ROS), which induce oxidative stress (Dubar et al. 2011, 2013). However, CQ-metal complexes other than ferroquine have not been fully examined against $P$. falciparum, especially when regarding their multistage spectrum of action and their in vivo efficacy.

From a pharmaceutical point of view, ruthenium is considered the most promising transition metal for drug development because of its safe and drugable profile (Meier et al. 2013; Maschke et al. 2014; Clavel et al. 2015). Regarding the use of CQ during composition of metal complexes, it presents a variety of advantages for drug development, especially pleiotropic effects and the possibility of tuning the spectrum of action by structural modification (Pérez et al. 2013; Lin et al. 2015; Huta et al. 2016). Bearing this in mind, we investigated here the activity of CQ-containing organoruthenium complexes. We found that, in addition to the classical activity of CQ against blood stages of P. falciparum, organoruthenium complexes presented a fast-action profile, promising activity against $P$. berghei liver stages and strong activity against gametocytes. Moreover, compounds presented in vivo efficacy and a mechanism of action involving toxic free heme accumulation in the parasite, which consequently induces oxidative stress.

\section{MATERIALS AND METHODS}

\section{Drugs and dilutions}

$\mathrm{CQ}$-containing organoruthenium complexes $(B C Q$, $M C Q, F C Q$ and $F F C Q$ ) and organoruthenium complex lacking $\mathrm{CQ}(F C L)$ were prepared as described in the literature (Colina-Vegas et al. 2015). All manipulations were carried out under argon using common Schlenk techniques. Solvents were purified by standard procedures immediately prior to use. Chloroquine, Mefloquine and Artesunate were supplied by FarManguinhos (Rio de Janeiro, Brazil). Primaquine was purchased from Sigma-Aldrich (St. Louis, MO). All drugs were dissolved in DMSO (PanReac, Barcelona, Spain) prior to use, and then diluted in culture medium. The final concentration of DMSO was less than $0 \cdot 5 \%$ in all in vitro experiments.

\section{Drug stability}

The stability of the complexes in solution was monitored using the ${ }^{1} \mathrm{H}$ NMR technique. Approximately $15 \mathrm{mg}$ of each complex was dissolved in DMSO- $d_{6}$ solution containing $20 \%$ of $\mathrm{D}_{2} \mathrm{O}$ (CIL, Tewksbury, MA) and incubated up to $60 \mathrm{~h}$. Aliquots were collected in the indicated time and analyzed on a $9.4 \mathrm{~T}$ Bruker Advance III (Billerica, MA) spectrometer with a $5 \mathrm{~mm}$ internal diameter indirect probe with Automatic Tuning Matching, holding the temperature stable at $300 \mathrm{~K}$.

\section{Animals}

Male Swiss Webster mice (4-6 weeks), housed at Centro de Pesquisas Gonçalo Moniz (Fundação Oswaldo Cruz, Bahia, Brazil), were maintained in sterilized cages under a controlled environment, receiving a rodent balanced diet and water ad libitum. All experiments were carried out in accordance with the recommendations of Ethical Issues Guidelines and were approved by the local Animal Ethics Committee (protocol number 016/2013).

\section{Cell culture}

CQ-sensitive 3D7 and CQ-resistant W2 strains of $P$. falciparum, NK65 strain of $P$. berghei as well as transgenic $P$. berghei expressing green fluorescent 
protein (GFP) and firefly luciferase (Luc), (PbGFPLuccon, parasite line $676 \mathrm{~m} 1 \mathrm{cl} 1)$ and $3 \mathrm{D} 7$ strain P. falciparum 3D7elo1-pfs-16-CBG99 expressing the Pyrophorus plagiophthalamus CBG99 luciferase under the gametocyte specific promoter pfs16 (Cevenini et al. 2014) were used here. P. falciparum was cultivated in human $\mathrm{O}^{+}$erythrocytes (donated by HEMOBA, Salvador, Brazil) at 5\% hematocrit with daily maintenance in Roswell Park Memorial Institute medium (RPMI-1640, Sigma-Aldrich) supplemented with $10 \% \mathrm{v} / \mathrm{v}$ human plasma (donated by HEMOBA, Salvador, Brazil), $25 \mathrm{~mm}$ HEPES (ChemCruz, Dallas, TX), $300 \mu \mathrm{M}$ hypoxanthine (MP Biomedicals, Santa Ana, CA), $11 \mathrm{~mm}$ glucose (Sigma-Aldrich) and $20 \mu \mathrm{g} \mathrm{mL}^{-1}$ of gentamicin (Life, Carlsbad, CA). Five days prior to use, $P$. falciparum was cultivated without hypoxanthine and synchronized to rings by $5 \%$ D-sorbitol (USB, Santa Clara, CA). Gametocytes were obtained from cultures of asexual parasites as described elsewhere (D'Alessandro et al. 2013). J774 macrophages were cultured in Dulbecco's modified Eagle's medium (DMEM) (Sigma-Aldrich) supplemented with $10 \%$ heat-inactivated fetal bovine serum (FBS, Gibco, Gaithersburg, MD) and $50 \mu \mathrm{g} \mathrm{mL}-1$ of gentamicin (Life). Hepatocellular carcinoma cells (HepG2) were cultivated in RPMI supplemented with $10 \%$ heat-inactivated FBS (Gibco) and $50 \mu \mathrm{g} \mathrm{mL}^{-1}$ of gentamicin (Life).

\section{Mammalian cell toxicity}

HepG 2 or J774 cells were seeded in $100 \mu \mathrm{L}$ of RPMI and DMEM, respectively, at $1 \times 10^{4}$ cells $\mathrm{mL}^{-1}$ in 96-well plates. Drugs were added $24 \mathrm{~h}$ later in a volume of $100 \mu \mathrm{L}$ suspended in medium and the plates were incubated for $72 \mathrm{~h}$ at $37^{\circ} \mathrm{C}$ and $5 \%$ $\mathrm{CO}_{2}$. Drugs were tested in eight concentrations $(150-0 \cdot 78 \mu \mathrm{M})$, each one in triplicate. Gentian violet (Synth) was used as positive control, while untreated cells were employed as negative controls. Then, $25 \mu \mathrm{L}$ of $10 \%$ AlamarBlue (Life) were added and incubated for $24 \mathrm{~h}$. Colorimetric readings were performed at 570 and $600 \mathrm{~nm}$ using SpectraMAx 190 instrument (Molecular Devices, Sunnyvale, $\mathrm{CA}) . \mathrm{CC}_{50}$ values were calculated using data-points gathered from three independent experiments.

\section{Drug-induced hemolysis}

Fresh and uninfected human $\mathrm{O}^{+}$erythrocytes were washed three-times with sterile phosphate-buffered saline (PBS), adjusted for $1 \%$ hematocrit and $100 \mu \mathrm{L}$ dispensed in a 96-well round bottom plate. Then, $100 \mu \mathrm{L}$ of drugs previously in DMSO and suspended in PBS were dispensed in the respective wells. Each drug was tested in seven concentrations $(100-0 \cdot 1 \mu \mathrm{M})$ assayed in triplicate. Untreated cells received $100 \mu \mathrm{L}$ of PBS containing $0 \cdot 5 \%$ DMSO (negative control), while positive controls received saponin (Sigma-Aldrich) at $1 \% \mathrm{v} / \mathrm{v}$. Plates were incubated for $1 \mathrm{~h}$ at $37^{\circ} \mathrm{C}$ under $5 \% \mathrm{CO}_{2}$. Plates were centrifuged at $1500 \mathrm{rpm}$ for $10 \mathrm{~min}$ and $100 \mu \mathrm{L}$ of supernatant were transferred to another plate, in which absorbance at $540 \mathrm{~nm}$ was measured using a SpectraMax 190 instrument. The percentage of hemolysis was calculated in comparison with positive and negative controls, and plotted against drug concentration generated using GraphPad Prism 5·01. Three independent experiments were performed.

\section{Cytostatic activity against intraerythrocytic P. falciparum}

One hundred $\mu \mathrm{L}$ of rings at $1 \%$ parasitaemia and $2.5 \%$ hematocrit in RPMI were dispensed in a 96well round bottom plate. Then, $100 \mu \mathrm{L}$ of drugs $(4 \cdot 0-0.003 \mu \mathrm{M})$ previously suspended in RPMI were dispensed in the respective wells. Each drug was tested in triplicate, in seven different concentrations. Untreated parasite samples received $100 \mu \mathrm{L}$ of medium containing $0.5 \%$ DMSO. Chloroquine and mefloquine were used as positive controls. Plates were incubated for $24 \mathrm{~h}$ at $37{ }^{\circ} \mathrm{C}$ under $3 \% \mathrm{O}_{2}, 5 \%$ $\mathrm{CO}_{2}$ and $91 \% \mathrm{~N}_{2}$ atmosphere. Then, $25 \mu \mathrm{L}$ of tritiated hypoxanthine $\left(0 \cdot 5 \mu \mathrm{Ci}\right.$ well ${ }^{-1}$, PerkinElmer, Shelton, CT) in RPMI was added to each well and incubated for $24 \mathrm{~h}$. Plates were frozen at $-20^{\circ} \mathrm{C}$ and subsequently thawed and the contents transferred to UniFilter-96 GF/B PEI coated plates (PerkinElmer) using a cell harvester. After drying, $50 \mu \mathrm{L}$ of scintillation cocktail (MaxiLight, Hidex, Turku, Finland) was added in each well, sealed and plate read in a liquid scintillation microplate counter (Chameleon, Turku, Finland). The per cent of inhibition was determined in comparison to untreated and inhibitory concentration for $50 \%$ $\left(\mathrm{IC}_{50}\right)$ values were determined by using non-linear regression with Logistic equation available at OriginPro $8 \cdot 5$. Three independent experiments were performed.

\section{Cytocidal activity against intraerythrocytic P. falciparum}

One hundred $\mu \mathrm{L}$ of trophozoites at $2 \%$ parasitaemia and $3 \cdot 0 \%$ hematocrit in RPMI were dispensed in a 96-well round bottom plate. Then, $100 \mu \mathrm{L}$ of drugs (10-0.07 $\mu \mathrm{M})$ previously suspended in RPMI were added to the respective wells. Each drug was tested in seven concentrations, each one in triplicate. Untreated parasites received $100 \mu \mathrm{L}$ of medium containing $0.5 \%$ DMSO, artesunate was used as positive control. Plates were incubated for $18 \mathrm{~h}$ at $37^{\circ} \mathrm{C}$ under $3 \% \mathrm{O}_{2}, 5 \% \mathrm{CO}_{2}$ and $91 \% \mathrm{~N}_{2}$ atmosphere. The plate was centrifuged three times with $200 \mu \mathrm{L}$ of drug-free medium at $1500 \mathrm{rpm}$ for $5 \mathrm{~min}$., then 
$200 \mu \mathrm{L}$ of media containing tritiated hypoxanthine was added and plate incubated for $48 \mathrm{~h}$. Plates were frozen at $-20{ }^{\circ} \mathrm{C}$ and thawed and transferred to UniFilter-96 GF/B PEI coated plates (PerkinElmer) using of a cell harvester. After drying, $50 \mu \mathrm{L}$ of scintillation cocktail was added in each well, sealed and plate read at liquid scintillation microplate counter. IC $_{50}$ values were determined employing non-linear regression with Logistic equation available in the OriginPro 8.5 software. Minimal parasiticidal concentration (MPC) was determined as the concentration that reduces parasite growth by $99 \pm 1 \cdot 0 \%$. At least three independent experiments were performed.

\section{Activity in the intraerythrocytic P. falciparum cycle}

A volume of $100 \mu \mathrm{L}$ of rings of $P$. falciparum W2 strain at $2 \%$ parasitemia and $2 \cdot 5 \%$ hematocrit in RPMI was dispensed per well in 96-well round bottom plates. Then, $100 \mu \mathrm{L}$ of drugs previously suspended in RPMI were added to the respective wells. Each drug concentration was tested in triplicate. Untreated parasite received $100 \mu \mathrm{L}$ of medium containing $0 \cdot 5 \%$ DMSO. Plates were incubated for $48 \mathrm{~h}$ at $37^{\circ} \mathrm{C}$ under $3 \% \mathrm{O}_{2}, 5 \% \mathrm{CO}_{2}, 91 \%$ $\mathrm{N}_{2}$ atmosphere followed by centrifugation three times with $200 \mu \mathrm{L}$ of drug-free medium at 1500 rpm for $5 \mathrm{~min}$. A volume of $200 \mu \mathrm{L}$ of media containing drugs were added and plates were incubated for additional $48 \mathrm{~h}$. Thin blood smears were then prepared, fixed and stained with quick panoptic stain (Laborclin, Pinhais, Brazil). Slides were observed in an optical microscope (Olympus CX41, St. Louis, MO). The number of rings, trophozoites and schizonts were counted in at least 1500 cells per slide $(n=4)$ and plotted against drug concentration generated using GraphPad Prism 5:01. Two independent experiments were performed.

\section{Activity against $\mathrm{P}$. berghei liver stages}

Inhibition of liver-stage infection by test compounds was determined by measuring the luminescence intensity in Huh-7 cells infected with a firefly luciferase-expressing $P$. berghei line as previously described (Ploemen et al. 2009). Briefly, Huh-7 cells, a human hepatoma cell line, were cultured in $1640 \mathrm{RPMI}$ medium supplemented with $10 \% \mathrm{v} / \mathrm{v}$ FBS, $1 \% \mathrm{v} / \mathrm{v}$ non-essential amino acids, $1 \% \mathrm{v} / \mathrm{v}$ penicillin/streptomycin, $1 \% \mathrm{v} / \mathrm{v}$ glutamine and $10 \mathrm{~mm}$ 4-(2-hydroxyethyl)-1-piperazineethanesulfonic acid (HEPES), $\mathrm{pH} 7$ and maintained at $37^{\circ} \mathrm{C}$ with $5 \% \mathrm{CO}_{2}$. For infection assays, Huh- 7 cells $\left(1 \cdot 0 \times 10^{4}\right.$ per well) were seeded in 96-well plates the day before drug treatment and infection. The medium was replaced by medium containing the appropriate concentration of each compound approximately $1 \mathrm{~h}$ prior to infection with sporozoites freshly obtained through disruption of salivary glands of infected female Anopheles stephensi mosquitoes. An amount of the DMSO solvent equivalent to that present in the highest compound concentration was used as control. Sporozoite addition was followed by centrifugation at $1700 \boldsymbol{g}$ for $5 \mathrm{~min}$. Parasite infection load was measured $48 \mathrm{~h}$ after infection by a bioluminescence assay (Biotium, Hayward, CA). The effect of the compounds on the viability of Huh-7 cells was assessed by the AlamarBlue assay (Life) using the manufacturer's protocol.

\section{Activity against $\mathrm{P}$. falciparum gametocytes}

Drugs were serially diluted in a 96-well round bottom plate (concentration range $29 \cdot 0-0 \cdot 22 \mu \mathrm{M}$ ) in $100 \mu \mathrm{L}$ per well. Then, $100 \mu \mathrm{L}$ of $3 \mathrm{D} 7 \mathrm{elo} 1-\mathrm{pfs} 16-$ CBG99 gametocytes at $0 \cdot 5-1 \%$ parasitaemia and $2 \%$ hematocrit were dispensed. Each drug was tested in triplicate, in seven different concentrations. The DMSO concentration was not toxic for gametocytes. Methylene blue was used as positive control. Plates were incubated for $72 \mathrm{~h}$ at $37{ }^{\circ} \mathrm{C}$ under $3 \%$ $\mathrm{O}_{2}, 5 \% \mathrm{CO}_{2}, 91 \% \mathrm{~N}_{2}$ atmosphere. Luciferase activity was taken as measure of gametocytes viability, as previously described in the literature (Cevenini et al. 2014). Briefly, $100 \mu \mathrm{L}$ of culture medium were removed from each well to increase hematocrit; $70 \mu \mathrm{L}$ of resuspended culture were transferred to a black 96 -well plate; $70 \mu \mathrm{L}$ of D-luciferin (1 mM in citrate buffer $0.1 \mathrm{M}, \mathrm{pH} \quad 5 \cdot 5)$ were added. Luminescence measurements were performed after $10 \mathrm{~min}$ with $500 \mathrm{~ms}$ integration time. The $\mathrm{IC}_{50}$ was extrapolated from the non-linear regression analysis of the concentration-response curve. The percentage of gametocytes viability was calculated as $100 \times$ [(OD treated sample - OD blank $) /(O D$ untreated sample $-\mu$ c-blank)] where 'blank' is the sample treated with $500 \mathrm{nM}$ of methylene blue, which completely kills gametocytes.

\section{Determination of the binding constant with ferriprotoporphyrin $I X$}

The association constant of organoruthenium complexes to ferriprotoporphyrin IX (Sigma-Aldrich) was measured as described previously (Egan et al. 1997). Titration of a $2 \mathrm{~mL}$ solution $(7 \cdot 5 \mu \mathrm{M}$ of ferriprotoporphyrin IX in $40 \%$ of DMSO, $\mathrm{pH} 7 \cdot 5)$ in presence of compound $(500 \mu \mathrm{M}$ in $40 \%$ of DMSO, $\mathrm{pH} 7 \cdot 5)$ was performed by UV absorbance at $\lambda=$ $402 \mathrm{~nm}$ using Hewlett Packard spectrophotometer, diode array model 8452 (Santa Clara, CA). The volume of each titration was $5 \mu \mathrm{L}$ and the relative molar ratio varied from 0 to 10 with regard to $\left[\mathrm{Fe}^{\mathrm{III}}\right.$-PPIX]. Spectra were recorded about $1 \mathrm{~min}$ after each addition. The absorption of all compounds was subtracted by adding the same 
amounts to the blank (40\% of DMSO, $\mathrm{pH} 7 \cdot 5)$. Fitting model with a 1:1 association using the equation described by Egan (Egan et al. 1997):

$$
A=\frac{A_{0}+A_{\infty} K[C]}{1+K[C]}
$$

where, $A_{0}$ is the absorbance of hemin before addition of complex or free chloroquine, $A_{\infty}$ is the absorbance for the drug-hemin adduct at saturation, $A$ is the absorbance at each point of the titration, and $K$ is the conditional association constant. Three independent experiments were performed.

\section{Assessment of inhibition of $\beta$-hematin formation by infrared spectroscopy}

Polymerization of hemin into $\beta$-hematin in acid acetate buffer was studied using the method previously described in the literature (Egan et al. 1994). Briefly, $12 \mathrm{mg}$ of hemin (Sigma-Aldrich) dissolved in $3 \mathrm{~mL}$ of $\mathrm{NaOH} 0.1 \mathrm{M}$ were added in $0.3 \mathrm{~mL}$ of $\mathrm{HCl} 0.1 \mathrm{M}$ and $1.7 \mathrm{~mL}$ of acetate buffer $10 \mathrm{M}$ $(\mathrm{pH} 5)$, keeping the temperature at $60^{\circ} \mathrm{C}$ during reaction. Primaquine and chloroquine were used as positive and negative controls, respectively. In a control test, after $0,10,30$ and $60 \mathrm{~min}, 1 \mathrm{~mL}$ of each solution was collected, cooled on ice for $10 \mathrm{~min}$, and then filtered over cellulose acetate $(0 \cdot 22 \mu \mathrm{m})$. The effect of the compounds was studied by performing the reaction as described above, adding three equivalents of each compound to the reaction mixture, where the reaction was stopped after $30 \mathrm{~min}$. prior acidification. Pellets were thoroughly washed with water in order to remove acetate salts. Each solid was dried in silica gel and $\mathrm{P}_{2} \mathrm{O}_{5}$ for $48 \mathrm{~h}$. Disks were mounted in $\mathrm{KBr}$ pellets and infrared spectra were analyzed in a Bomem-Michelson FT MB-102 instrument in the $4000-200 \mathrm{~cm}^{-1}$ region. Three independent experiments were performed.

\section{Assessment of inhibition of $\beta$-hematin formation by $U V$-Vis spectroscopy}

The assay was performed according to the method previously described in the literature (Parapini et al. 2000). A solution of hemin chloride $(50 \mu \mathrm{L}$, $4 \mathrm{~mm}$ ) dissolved in DMSO was distributed in 96well plates. Different concentrations (1-100 mM) of each complex was dissolved in DMSO and added in triplicate $(50 \mu \mathrm{L})$ to a final concentration of $1 \cdot 25-25 \mathrm{~mm}$ well ${ }^{-1}$. Control contained water or DMSO. The formation of $\beta$-hematin was initiated by addition of acetate buffer $(100 \mu \mathrm{L}, 0 \cdot 2 \mathrm{M}, \mathrm{pH}$ $4 \cdot 4)$. The plates were incubated at $37^{\circ} \mathrm{C}$ for $48 \mathrm{~h}$ and then centrifuged. After removing the supernatant, the solid was washed twice with DMSO and finally dissolved in $\mathrm{NaOH}(200 \mu \mathrm{L}, 0 \cdot 2 \mathrm{~N})$. After diluting with $\mathrm{NaOH}(0 \cdot 1 \mathrm{~N})$, absorbance was measured at $405 \mathrm{~nm}$ in a spectrophotometer. The inhibition of $\beta$-hematin was calculated in comparison with negative control, plotted against drug concentration generated using GraphPad Prism 5:01. Three independent experiments were performed.

\section{SYTO 61 staining of $\mathrm{P}$. falciparum}

$100 \mu \mathrm{L}$ of rings of $P$. falciparum $3 \mathrm{D} 7$ strain at $2 \%$ parasitemia and $2 \cdot 0 \%$ hematocrit in RPMI were dispensed in a 96-well round bottom plate. Then, $100 \mu \mathrm{L}$ of drugs previously suspended in RPMI were added to the respective wells. Each drug concentration was tested in triplicate. Untreated parasite received $100 \mu \mathrm{L}$ of medium containing $0.5 \%$ DMSO. Plates were incubated for $48 \mathrm{~h}$ at $37{ }^{\circ} \mathrm{C}$ under $3 \% \mathrm{O}_{2}, 5 \% \mathrm{CO}_{2}, 91 \% \mathrm{~N}_{2}$ atmosphere. Plate was centrifuged with $200 \mu \mathrm{L}$ of drug-free medium at $1500 \mathrm{rpm}$ for $5 \mathrm{~min}$. and $100 \mu \mathrm{L}$ of SYTO 61 (Life) at $0.5 \mu \mathrm{M}$ suspended in medium was added to each well and incubated in the dark for $30 \mathrm{~min}$. After washing and adding $400 \mu \mathrm{L}$ of isoton diluent, samples were analyzed in a flow cytometer (LSRFortessa, BD, Franklin Lakes, NJ). Gate of infected cells was determined in comparison with uninfected control. At least 200.000 events were acquired in the allophycocyanin channel $(633,660$ $\mathrm{nm})$. The analysis was performed using FlowJo (LLC, Ashland, Covington, LA). Three independent experiments were recorded.

\section{CM-H2-DCFDA and SYTO 61 staining of $\mathrm{P}$. falciparum}

A volume of $100 \mu \mathrm{L}$ of rings of $P$. falciparum 3D7 strain at $3 \cdot 0 \%$ parasitaemia and $1 \cdot 0 \%$ hematocrit in RPMI were dispensed per well in a 96-well round bottom plate. A volume of $25 \mu \mathrm{L}$ of CM-H2DCFDA (Life) at $15 \mu \mathrm{M}$ suspended in media was added to each well and incubated in the dark for 20 min. Then, $100 \mu \mathrm{L}$ of drugs previously suspended in RPMI were added to the respective wells. Each drug concentration was tested in triplicate. Untreated parasite received $100 \mu \mathrm{L}$ of medium containing $0 \cdot 5 \%$ DMSO. Plates were incubated for $3 \cdot 5$ h at $37{ }^{\circ} \mathrm{C}$ under $3 \% \mathrm{O}_{2}, 5 \% \mathrm{CO}_{2}, 91 \% \mathrm{~N}_{2}$ atmosphere. A volume of $25 \mu \mathrm{L}$ of SYTO 61 (Life) at $0.5 \mu \mathrm{M}$ suspended in media was added to each well and incubated in the dark for $30 \mathrm{~min}$. Plates were centrifuged at $1500 \mathrm{rpm}$ for $5 \mathrm{~min}$, supernatant was discarded and $200 \mu \mathrm{L}$ of isoton diluent was added and samples were analyzed in a flow cytometer (LSRFortessa, $\mathrm{BD})$. Gate of infected cells was determined in comparison with uninfected control. At least 200.000 events were acquired in the fluorescein isothiocyanate channel $(488,585 \mathrm{~nm})$ for CM-H2-DCFDA and allophycocyanin channel $(633,660 \mathrm{~nm})$ for SYTO 61. The analysis was performed using FlowJo (LLC), in three independent experiments. 


\section{In vivo blood schizontocidal activity}

Male Swiss Webster mice (4-6 weeks) were infected by intraperitoneal injection of $10^{6}$ NK65 strain P. bergheiinfected erythrocytes and randomly divided into groups of $n=5$. Each drug was solubilized in DMSO/saline $(20: 80 \mathrm{v} / \mathrm{v})$ prior administration. Treatment was initiated within $3 \mathrm{~h}$ post-infection and given daily for 4 consecutive days orally by gavage or by intraperitoneal injection of $100 \mu \mathrm{L}$. Chloroquine treated mice were used as positive control group, while untreated infected mice were used as negative control group. The following parameters were evaluated: parasitaemia counted at 4, 5, 6, 7 and 8 days post-infection and 30 days post-infection animal survival. The per cent of parasitaemia reduction was calculated as follows ([mean vehicle group - mean treated group)/mean vehicle group $] \times 100 \%$ ). Two independent experiments were performed.

\section{Ex vivo drug-induced cardiotoxicity in rat hearts using Langendorff system}

Male Wistar rats of 6-8 weeks-old were heparinized (800 IU kg${ }^{-1}$, i.p.) and following $20 \mathrm{~min}$ anaesthetized with ketamine $\left(90 \mathrm{mg} \mathrm{kg}^{-1}\right.$, i.p.) and xylazine $(10 \mathrm{mg}$ $\mathrm{kg}^{-1}$, i.p.). Heart was quickly excised via thoracotomy and immediately cannulated through the aorta to retrograde perfusion on the Langendorff system apparatus with peristaltic pump Minipuls 3 (Peristaltic Pump, ADInstruments, Sydney, Australia) under constant flow $6.5 \mathrm{~mL} \mathrm{~min}^{-1}$. The heart was immersed in Krebs-Henseleit buffer (KHB) solution containing (in $\mathrm{mM}): \quad 4.7 \mathrm{KCl}, \quad 1.2 \mathrm{KH}_{2} \mathrm{PO}_{4}, \quad 118 \mathrm{NaCl}, \quad 25$ $\mathrm{Na}_{2} \mathrm{HCO}_{3}, 1.2 \mathrm{MgSO}_{4}, 1.75 \mathrm{CaCl}_{2}, 0.5 \mathrm{EDTA}$ and 8.0 D-glucose, $\mathrm{pH} 7 \cdot 4 ; 37^{\circ} \mathrm{C} ; 5 \% \mathrm{CO}_{2}$, warmed to $37^{\circ} \mathrm{C}$. Two electrodes were then positioned at atrium and ventricle to obtain optimal electrocardiographic recordings. These electrodes were connected to the differential inputs of a Bioamplifier (PowerLab 8/ 35, AD Instrument) and a third was connected to ground. Recordings were displayed on a computer. Experimental protocol consisted of taking control records for $20 \mathrm{~min}$ in Krebs' solution, 10-min, perfusion period with MCQ or FCQ drugs $(0 \cdot 1 ; 1 \cdot 0$ and $10 \mu \mathrm{g} \mathrm{mL}^{-1}$ ) dissolved in DMSO and suspended in $\mathrm{KHB}$ solution and a return to Krebs' solution for $20 \mathrm{~min}$. Each drug was tested in triplicate at the three different concentrations. Electrocardiography recordings were registered as the presence of arrhythmias, heart rate, ventricular activation time, PR intervals, amplitude and time intervals of QT waves. Each drug was tested in at least three isolated hearts, LabChart Pro software including blood pressure and ECG analysis was used.

\section{Statistical analyses}

Non-linear regression analysis was used to calculate $\mathrm{CC}_{50}$ and $\mathrm{IC}_{50}$ values by using GraphPad Prism version 5.01 (Graph Pad Software, San Diego, USA), OriginPro version 8.5 (OriginLab, Northampton, USA) or Gen5 1.10 software provided with the Synergy4 plate reader (Biotek, Winooski, USA). One-way ANOVA analysis and Bonferroni multiple comparison tests were used. Results were considered statistically significant when $P<0.05$ as analysed by GraphPad Prism version 5.01.

\section{RESULTS}

\section{Chemical structure and stability of organoruthenium complexes}

The structures of organoruthenium complexes with general formula $\left[\mathrm{RuCQ}\left(\eta^{6}-\mathrm{C}_{10} \mathrm{H}_{14}\right)(\mathrm{N}-\mathrm{N})\right]^{2+}$ studied in this work are shown in Fig. 1 , where $\eta^{6}-\mathrm{C}_{10} \mathrm{H}_{14}$ is $\alpha$-phellandrene and $\mathrm{N}-\mathrm{N}$ is $2^{\prime}$-bipyridine $(B C Q)$, 5,5'-dimethyl-2,2'-bipyridine ( $M C Q), 1,10$-phenanthroline $(F C Q)$, 4,7-diphenyl-1,10-phenanthroline $(F F C Q)$. An organoruthenium complex lacking $\mathrm{CQ}$ in its composition, named FCL, was used during pharmacological evaluation. All these complexes were previously characterized by usual chemical tools (Colina-Vegas et al. 2015). To assess whether these organoruthenium complexes are dissociating in cell culture media and releasing CQ, stability in $80 \%$ DMSO- $d_{6}$ and $20 \% \mathrm{D}_{2} \mathrm{O}$ solution was monitored by ${ }^{1} \mathrm{H}$ NMR at different times up to $60 \mathrm{~h}$. Spectra of $F C Q$ samples are shown in Fig. 2. Any modification in intensity and chemical shifts were observed in the spectra up $60 \mathrm{~h}$ of incubation time. The same profile was observed after the monitoring of $M C Q$ samples (data not shown).

\section{Organoruthenium complexes are active against asexual blood stages and display low toxicity against mammalian cells}

The mean $\mathrm{IC}_{50}$ values of the compounds were determined against CQ-sensitive and CQ-resistant strains of $P$. falciparum, while the $\mathrm{CC}_{50}$ values in mammalian cells were determined against J774 macrophages and HepG2 hepatocellular cells (Table 1). In the CQ-sensitive strain, all complexes were 2 -fold less active than $\mathrm{CQ}$. In the CQ-resistant strain, with the exception of compound $F F C Q$, the activity of complexes was similar to that of CQ. Apart from the FFCQ complex, susceptibility to drugs tested was in general similar for CQ-sensitive and CQ -resistant strains. Complexes did not either cause hemolysis in concentration up $100 \mu \mathrm{M}$ (Fig. S1, supporting information) or cardiotoxicity in ex vivo isolated rat hearts (Table S1, supporting information). Regarding mammalian cytotoxicity, $\mathrm{CC}_{50} \mathrm{~s}$ for complexes were 5- to 10 -fold higher than for the reference drug gentian violet. The only exception was observed for the $F F C Q$ compound, which was cytotoxic in low micromolar concentrations. The cytotoxicity of complexes 

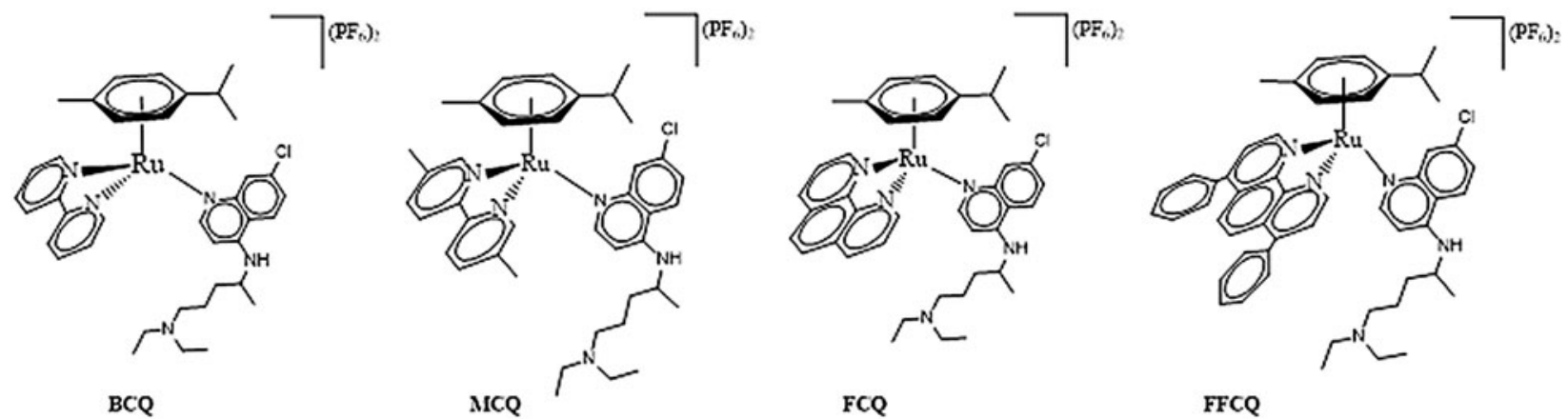

Fig. 1. Chemical structures of organoruthenium complexes.

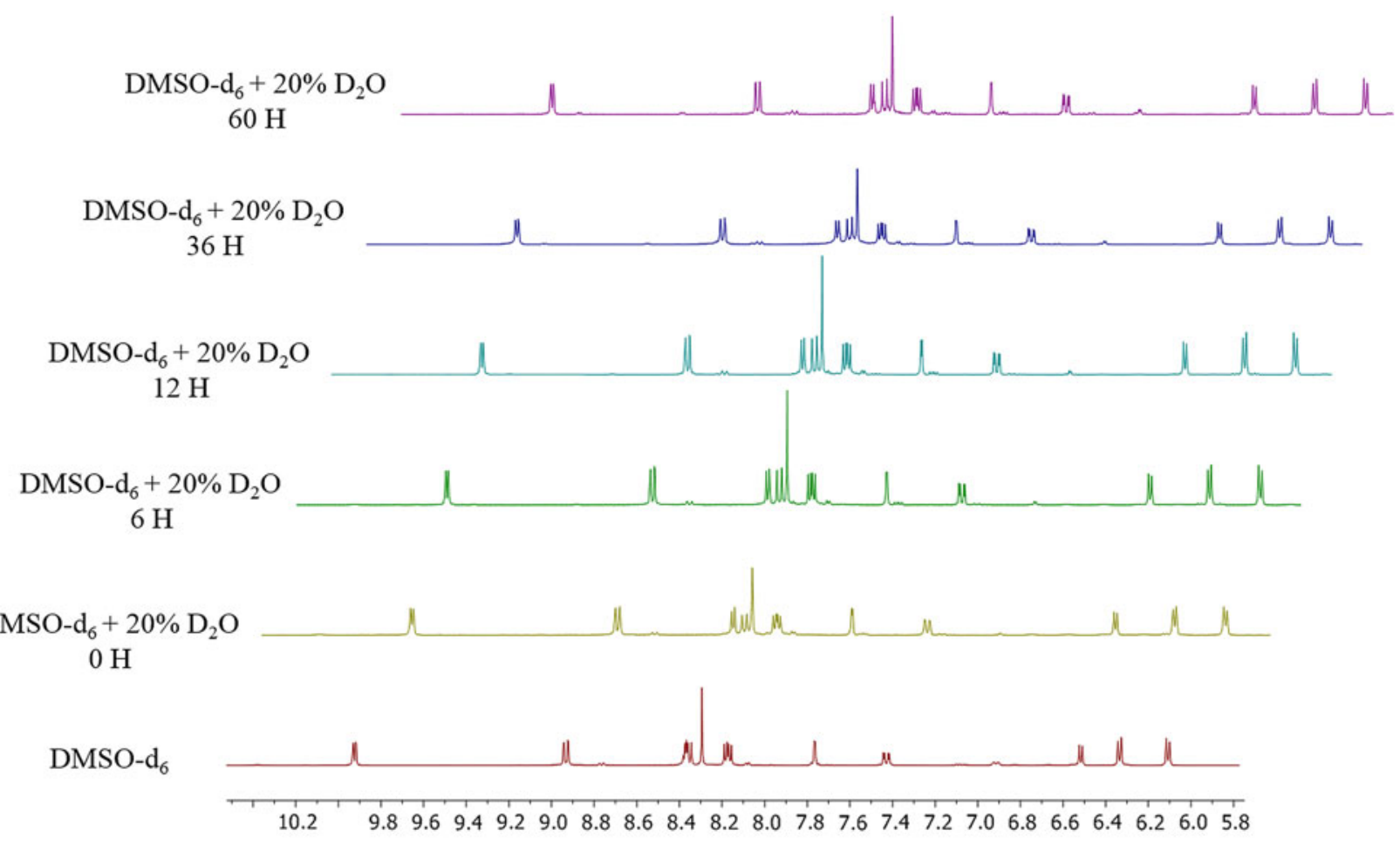

Fig. 2. Organoruthenium complexes stability in aqueous solution in incubation up to $60 \mathrm{~h} .{ }^{1} \mathrm{H}-\mathrm{NMR}$ spectra of $F C Q$ complex in DMSO- $d_{6}$ containing $20 \%$ of $\mathrm{D}_{2} \mathrm{O}$. The incubation times are displayed in the left side. At least two independent experiments were performed.

was similar or lower than that of CQ. Calculated selectivity index (SI) values of 513 and 450 were obtained for $F C Q$ and $B C Q$, respectively, which are similar or higher than that of $\mathrm{CQ}$. Of note, the FCL complex showed low antiparasitic activity and SI values several folds lower than CQ-ruthenium complexes.

\section{Organoruthenium complexes impair asexual parasite differentiation}

Once antiparasitic activity had been observed, the onset of action and the activity against erythrocytic parasite cycle was investigated for $M C Q$ and $F C Q$ complexes (Fig. 3). Treatment with an $\mathrm{IC}_{50}$ concentration of $M C Q$ decreased parasitaemia at the onset of drug exposure, while an accumulation of parasites in the trophozoite stage and consequent impairment to schizont progression were observed $96 \mathrm{~h}$ post exposure. In the presence of approximately 2-fold the $\mathrm{IC}_{50}$ of $M C Q$, substantial accumulation of trophozoites was achieved $48 \mathrm{~h}$ post exposure, while progression in parasite growth and differentiation was abrogated $96 \mathrm{~h}$ post exposure. Similar treatments with $F C Q$ led to a similar impairment on parasite cycle at the $\mathrm{IC}_{50}$ values of the drugs and complete blockage of the parasite cycle twice that concentration. A morphological examination of stained blood smears revealed that during treatment with the $\mathrm{IC}_{50}$ concentration of $M C Q$ and $F C Q$, digestive vacuoles containing hemozoin crystals were absent in trophozoites (data not shown). This is typically observed for CQ, a well-known hemozoin inhibitor. At higher concentration of complexes, most parasites appeared as a picnotic mass. 
Table 1. Cytostatic activity against intraerythrocytic $P$. falciparum, mammalian cell cytotoxicity and selectivity indexes of organoruthenium complexes

\begin{tabular}{|c|c|c|c|c|c|c|}
\hline \multirow[b]{2}{*}{ Compounds } & \multicolumn{2}{|c|}{ P. falciparum, $\mathrm{IC}_{50} \pm$ s.Е.м. $(\mu \mathrm{M})^{\mathrm{a}}$} & \multicolumn{2}{|c|}{ Cells, $\mathrm{CC}_{50} \pm$ s.E.M. $(\mu \mathrm{M})^{\mathrm{b}}$} & \multicolumn{2}{|c|}{$\begin{array}{l}\text { Selectivity } \\
\text { index }^{c}\end{array}$} \\
\hline & CQ-sensitive 3D7 & CQ-resistant W2 & $\mathrm{J} 774$ & HepG2 & $3 \mathrm{D} 7$ & W2 \\
\hline FCL & $3 \cdot 4 \pm 0 \cdot 75$ & $4 \cdot 6 \pm 0 \cdot 54$ & $111 \cdot 3 \pm 51$ & $29 \cdot 7 \pm 2 \cdot 6$ & 32 & 23 \\
\hline $\mathrm{BCQ}$ & $0 \cdot 34 \pm 0 \cdot 13$ & $0.52 \pm 0.04$ & $153 \cdot 9 \pm 6 \cdot 3$ & $>300$ & 450 & 307 \\
\hline MCQ & $0 \cdot 30 \pm 0 \cdot 007$ & $0 \cdot 30 \pm 0 \cdot 1$ & $42 \cdot 6 . \pm 1 \cdot 6$ & $77 \cdot 7 \pm 1 \cdot 4$ & 142 & 142 \\
\hline $\mathrm{FCQ}$ & $0 \cdot 30 \pm 0 \cdot 03$ & $0 \cdot 31 \pm 0 \cdot 01$ & $154 \cdot 0 \pm 6 \cdot 9$ & $84 \cdot 9 \pm 2 \cdot 2$ & 513 & 513 \\
\hline FFCQ & $0 \cdot 21 \pm 0 \cdot 039$ & $2 \cdot 1 \pm 0 \cdot 3$ & $2 \cdot 4 \pm 0 \cdot 2$ & $21 \cdot 2 \pm 0 \cdot 8$ & 11 & 1 \\
\hline $\mathrm{CQ}$ & $0 \cdot 11 \pm 0 \cdot 035$ & $0 \cdot 43 \pm 0 \cdot 09$ & $37 \cdot 6 \pm 3 \cdot 6$ & $76 \cdot 1 \pm 3 \cdot 1$ & 690 & 190 \\
\hline Mefloquine & - & $0 \cdot 0035 \pm 0 \cdot 0004$ & - & - & - & - \\
\hline Gentian violet & - & - & $4 \cdot 3 \pm 0 \cdot 8$ & $14 \cdot 2 \pm 0 \cdot 3$ & - & - \\
\hline
\end{tabular}

a Determined $48 \mathrm{~h}$ after incubation with compounds.

b Determined $72 \mathrm{~h}$ after incubation with compounds. Values were calculated as mean of three independent experiments.

${ }^{c}$ Determined as $\mathrm{CC}_{50}(\mathrm{~J} 774$ cells $) / \mathrm{IC}_{50}$. $\mathrm{IC}_{50}$, inhibitory concentration at $50 \% . \mathrm{CC}_{50}$, cytotoxic concentration at $50 \%$. S.E.M., standard error of the mean.

\section{Organoruthenium complexes are fast-acting parasiticidal agents against asexual blood stages}

To assess the parasiticidal activity of complexes, time- and concentration-dependent effects were studied in synchronized P. falciparum trophozoites. Growth inhibition by drug exposure for 6, 18, 24 or $48 \mathrm{~h}$ was monitored by microscopy examination. At $2 \times$ the $\mathrm{IC}_{50}$ values of the $F C Q$ and $M C Q$, parasite inhibition was detected after $18 \mathrm{~h}$ of compound exposure (data not shown). This incubation time was selected for the parasiticidal activity study. After $18 \mathrm{~h}$ of exposure to different drug concentrations, followed by extensive washing to remove drugs, the culture was maintained for $48 \mathrm{~h}$ and growth was quantified by hypoxanthine incorporation relative to untreated control. Artesunate was used as a positive control. Parasite clearance was estimated as $99 \pm 1 \cdot 0 \%$ parasite growth and expressed as MPC. Table 2 shows mean $\mathrm{LC}_{50}$ and MPC values. Complexes show parasiticidal activity, with $\mathrm{LC}_{50}$ values comparable with $\mathrm{CQ}$. MPC values show that $M C Q$ was more potent than $F C Q$. The parasiticidal potency of the complexes was lower than artesunate but higher than CQ, which did not lead to parasite clearance in concentrations up $10 \mu \mathrm{M}$.

\section{Antiparasitic activity is not governed by inhibition of $\beta$-hematin formation}

Given their potent in vitro growth inhibition against trophozoites, the effects of organoruthenium complexes within hemin polymerization as well as their interaction to ferriprotoporphyrin IX ( $\alpha$-hematin) were investigated. Firstly, we determined the binding constant to ferriprotoporphyrin IX by analyzing the absorption spectra at various concentrations of complexes. As shown in Fig. 4, increasing the concentration of complex caused a reduction in the absorption intensity, ranging from 60 to $70 \%$. These titration curves were further fitted to a $1: 1$ association model to give the binding constant values expressed as $\log \mathrm{K}$ (Table 3 ). LogK values for organoruthenium complexes were lower than the observed for CQ and in general, there was no great difference when the complexes were compared with each other.

After measuring the interaction with hematin, the compounds' ability to inhibit hemin aggregation into $\beta$-hematin was evaluated by UV-Vis spectroscopy analysis (Soret's porphyrin band). This experiment was performed in acetate buffer at $\mathrm{pH} 4.9$ and determined $48 \mathrm{~h}$ after incubation (Table 3). Comparison of $\mathrm{IC}_{50}$ values revealed that $F F C Q$ complex was unable to inhibit hemin aggregation process in concentration up $2.0 \mathrm{~mm}$. In contrast, other organoruthenium complexes inhibited hemin aggregation with potency similar to CQ. Additionally, the hemin aggregation process was evaluated by infrared spectra. Figure S2 illustrates the infrared spectrum of hemin in the absence or presence of $\mathrm{CQ}$, primaquine and organoruthenium complexes. Over time, hemin aggregates into $\beta$-hematin, leading to the formation of iron-carboxylate bonds observed as bands at 1.660 and $1.210 \mathrm{~cm}^{-1}$. Adding primaquine did not impair $\beta$-hematin formation, while adding $\mathrm{CQ}$ or its ruthenium complexes inhibited $\beta$-hematin formation.

\section{Oxidative stress induced by organoruthenium treatment}

Firstly, we determined parasite viability in 3D7 strain trophozoites by staining with SYTO 61 accordingly to a previously described protocol $(\mathrm{Fu}$ et al. 2010) and analyzing by flow cytometry. 


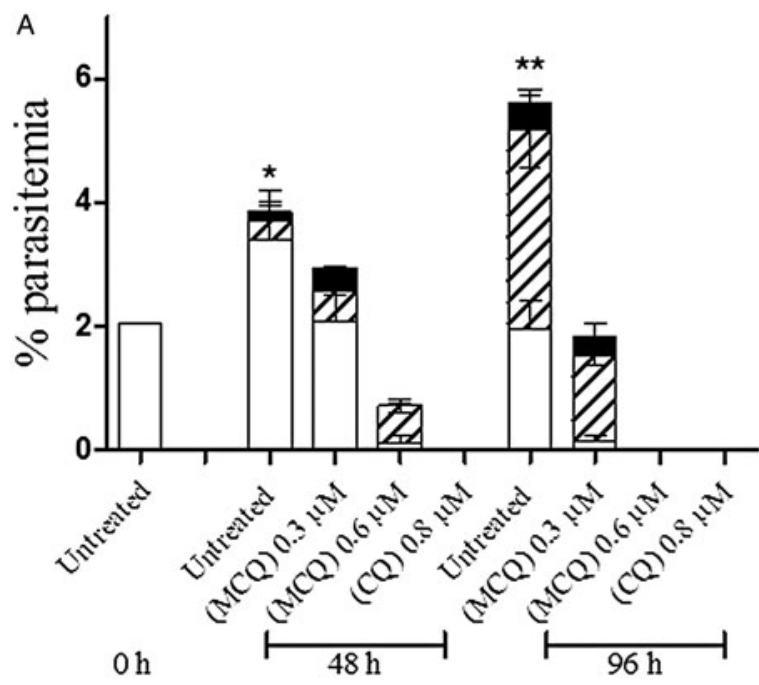

B

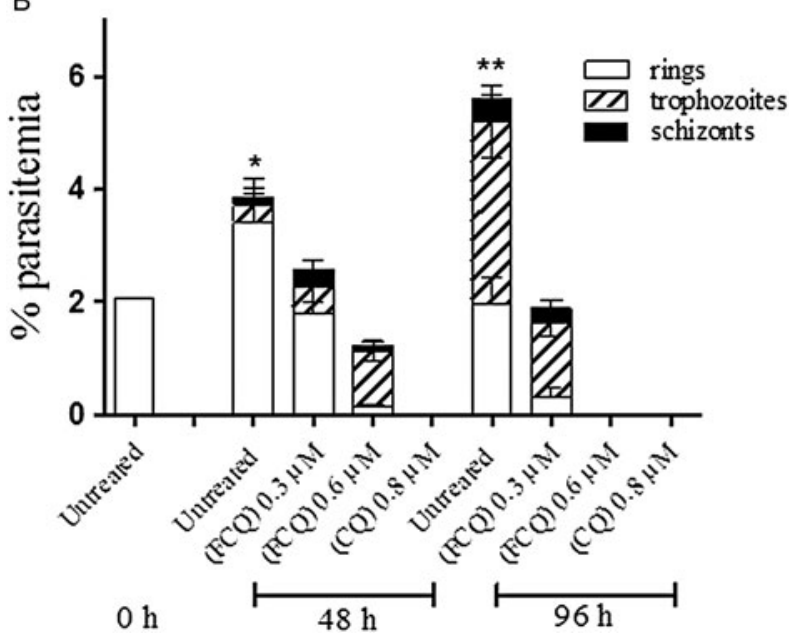

Fig. 3. Drug-susceptibility testing against blood stage W2 strain P. falciparum. Ring stage parasites ( $\%$ parasitaemia, $2 \cdot 5 \%$ hematocrit) were incubated with vehicle (DMSO $0 \cdot 5 \%$ ) as a untreated control, CQ, $M C Q$ (panel A) and $F C Q$ (panel B) at 0 and $48 \mathrm{~h}$. Quantification of intraerythrocytic stages at 48 and 96 after addition of the compounds are shown. Values are shown from one of two independent experiments. Error bars represent standard deviation. $* p<0.05$ for quantification of rings $v s$ untreated $0 \mathrm{~h} .{ }^{*} * p<0.05$ for quantification of trophozoites $v s$ untreated $48 \mathrm{~h}$. CQ, chloroquine.
Treatment at $1 \cdot 25 \mu \mathrm{M}$ of CQ, $M C Q$ and $F C Q$ for 48 $\mathrm{h}$ incubation time led a population of non-viable parasites, while at $0 \cdot 31 \mu \mathrm{M}$ we observed two populations: a non-viable population and another that is viable but with decreased SYTO 61 staining, possible due to delay in parasite growth (Fig. S3, supporting information). Trophozoites were treated with CQ or complexes and incubated for $4 \mathrm{~h}$ and co-labelled with ROS probe CM-H2DCFDA and SYTO 61 (Fig. S4, supporting information). Parasite viability following treatment at $0.15 \mu \mathrm{M}$ and monitored by SYTO 61 staining was not altered in comparison to untreated parasites (Fig. 5). In contrast, at the same incubation and treatment, $M C Q$ and $F C Q$ increased DCF fluorescence levels in approximately 2-fold in comparison with untreated parasites. CQ treatment at same concentration increased in approximately $50 \%$ DCF fluorescence, while the complex lacking $\mathrm{CQ}$ in its composition $(F C L)$ did not increase DCF when compared with untreated parasites.

\section{Multistage action of organoruthenium complexes}

We next examined whether ruthenium complexes possess multistage activity. Firstly, the ability to inhibit Plasmodium hepatic infection was assessed in a well-established in vitro infection model, employing $P$. berghei-infected Huh7 cells, a human hepatoma cell line (Prudêncio et al. 2011). Huh7 cells were cultured in the presence of each complex followed by addition of luciferase-expressing $P$. berghei sporozoites. Infection load and host cell cytotoxicity were analyzed $48 \mathrm{~h}$ post-infection. Primaquine, the only licensed drug against Plasmodium liver stages (Rodrigues et al. 2012), was used as the reference drug. As shown in Fig. 6, the $F C Q$ compound did not decrease infection in comparison to the untreated control. The $M C Q$ compound inhibited approximately 50\% infection at a $10 \mu \mathrm{M}$ concentration, without affecting host cell confluency. A similar concentration of primaquine inhibited infection by $50 \%$. For comparison, CQ

Table 2. In vitro parasiticidal property of organoruthenium complexes against intraerythrocytic $P$. falciparum

\begin{tabular}{|c|c|c|c|c|}
\hline \multirow[b]{2}{*}{ Compounds } & \multicolumn{2}{|l|}{$\mathrm{CQ}$-sensitive $3 \mathrm{D}^{\mathrm{a}}$} & \multicolumn{2}{|l|}{ CQ-resistant $\mathrm{W} 2^{\mathrm{a}}$} \\
\hline & $\mathrm{LC}_{50} \pm$ s.E.M. $(\mu \mathrm{M})^{\mathrm{b}}$ & $\operatorname{MPC}(\mu \mathrm{M})^{\mathrm{c}}$ & $\mathrm{LC}_{50} \pm$ s.E.M. $(\mu \mathrm{M})^{\mathrm{b}}$ & $\operatorname{MPC}(\mu \mathrm{M})^{\mathrm{c}}$ \\
\hline MCQ & $0 \cdot 81 \pm 0 \cdot 073$ & $5 \cdot 0$ & $0 \cdot 37 \pm 0 \cdot 017$ & $2 \cdot 5$ \\
\hline $\mathrm{FCQ}$ & $1.05 \pm 0.078$ & $5 \cdot 0$ & $0.87 \pm 0.04$ & $5 \cdot 0$ \\
\hline $\mathrm{CQ}$ & $0 \cdot 64 \pm 0.04$ & $>10$ & $0.43 \pm 0.03$ & $>10$ \\
\hline Artesunate & $0 \cdot 0053 \pm 0.00032$ & $0 \cdot 12$ & $0.0049 \pm 0.0009$ & $0 \cdot 19$ \\
\hline
\end{tabular}

a Activity determined in trophozoites incubated for $18 \mathrm{~h}$ with drugs then for $48 \mathrm{~h}$ in drug-free conditions.

b $\mathrm{LC}_{50}$, lethal concentration at $50 \%$.

c MPC, minimal parasiticidal concentration. 

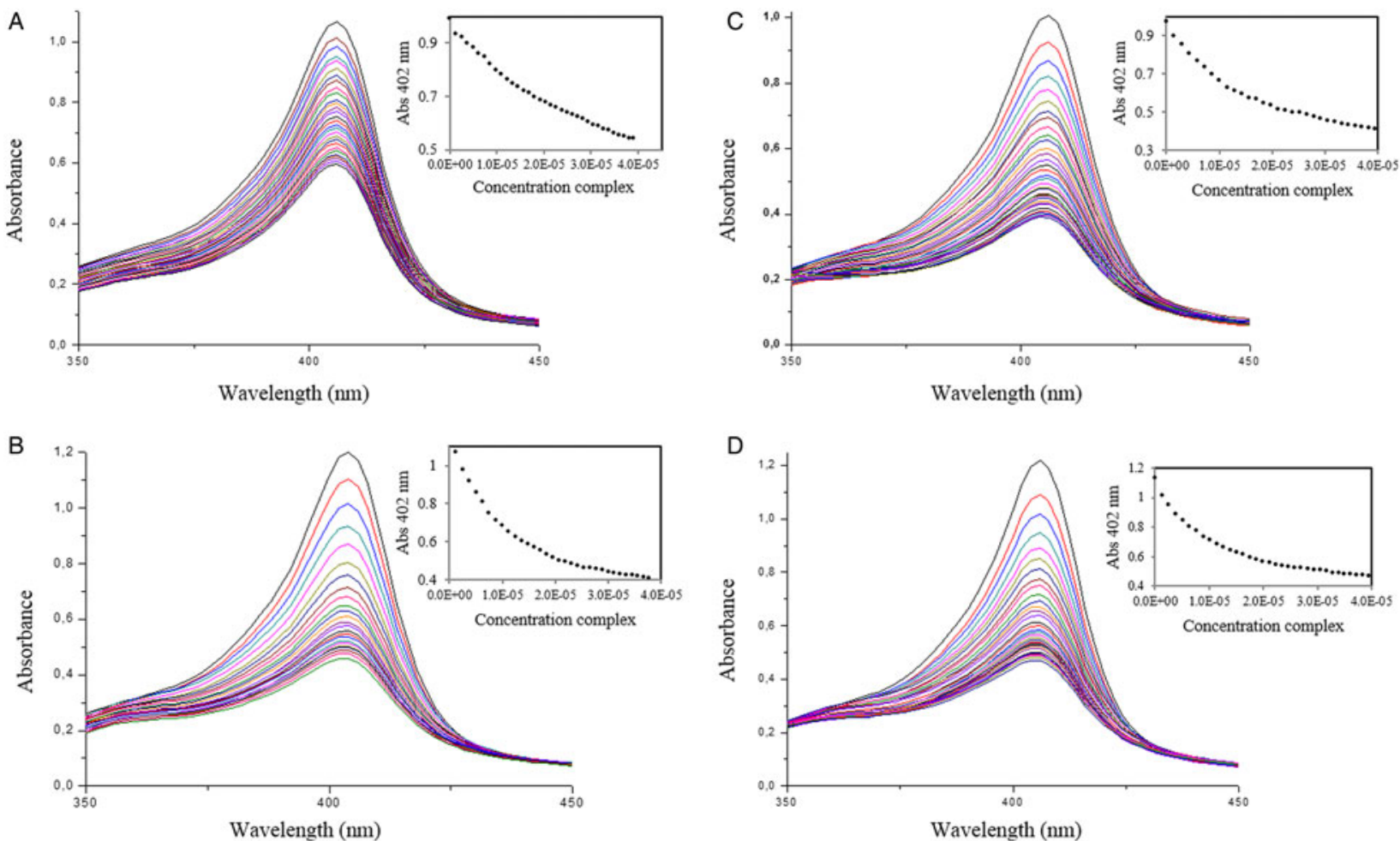

Fig. 4. Spectroscopic titration of Fe(III)PPIX at pH 7·4 with organoruthenium complexes. Panel A, FCQ complex; Panel B, FFCQ complex; Panel C, BCQ complex; Panel 4, $M C Q$ complex.

Table 3. Binding constant for hematin and inhibition of hemin polymerization for organoruthenium complexes

\begin{tabular}{|c|c|c|c|c|}
\hline \multirow[b]{3}{*}{ Compounds } & \multicolumn{2}{|l|}{ Hematin } & \multirow{2}{*}{\multicolumn{2}{|c|}{ Hemin }} \\
\hline & \multicolumn{2}{|c|}{$\mathrm{UV}-\mathrm{vis}$ titration } & & \\
\hline & $\log \mathrm{K}^{\mathrm{a}}$ & $\%$ hypochromism ${ }^{\mathrm{b}}$ & $\mathrm{IC}_{50} \pm$ S.D. $(\mathrm{mM})^{\mathrm{c}}$ & $\begin{array}{l}\text { Presence of peaks at } \\
1660 \text { and } 1210 \mathrm{~cm}^{-1}\end{array}$ \\
\hline BCQ & $4 \cdot 77 \pm 0 \cdot 04$ & 58 & $0 \cdot 30 \pm 0 \cdot 11$ & - \\
\hline MCQ & $4.98 \pm 0.05$ & 60 & $0.43 \pm 0.03$ & - \\
\hline FCQ & $4 \cdot 44 \pm 0 \cdot 03$ & 57 & $0 \cdot 50 \pm 0 \cdot 01$ & - \\
\hline FFCQ & $5 \cdot 02 \pm 0 \cdot 01$ & 62 & $>2 \cdot 0$ & - \\
\hline CQ & $5 \cdot 09 \pm 0 \cdot 02$ & 55 & $0 \cdot 40 \pm 0 \cdot 11$ & - \\
\hline PQ & - & - & - & + \\
\hline
\end{tabular}

${ }^{a}$ Binding constant expressed as $\log \mathrm{K}$.

b Determined in comparison with untreated (no drug).

c Determined $48 \mathrm{~h}$ after drug incubation.

d Determined by infrared spectrum.

reduces hepatic infection by $50 \%$ at a $15 \mu \mathrm{M}$ concentration (Rodrigues et al. 2012). We then assessed the transmission-blocking potential of each compound against stage $\mathrm{V} \quad P$. falciparum gametocytes. Inhibition of viability of stage V P. falciparum 3D7 gametocytes was evaluated and the compounds' $\mathrm{IC}_{50}$ values were determined. Methylene blue was used as positive control (Table 4). In concentrations up $14 \mu \mathrm{M}$, the $M C Q$ complex did not inhibit gametocytes, while the $F C Q$ and $F F C Q$ complexes presented inhibitory activity. The $B C Q$ complex was the most potent, exhibiting an $\mathrm{IC}_{50}$ value in the low micromolar range. Although less potent than methylene blue, this compound was active, while $\mathrm{CQ}$ is inactive in impairing gametocyte viability.

\section{Organoruthenium complexes reduce parasitaemia in infected mice}

Before evaluating efficacy, compounds were examined regarding lethal doses in Swiss Webster mice $(n=3)$. A single intraperitoneal injection of $M C Q$ or $B C Q$ was not lethal at a dose of $50 \mathrm{mg} \mathrm{kg}^{-1}$ weight ${ }^{-1} . F C Q$ was lethal at $50 \mathrm{mg} \mathrm{kg}^{-1}$, but safer 


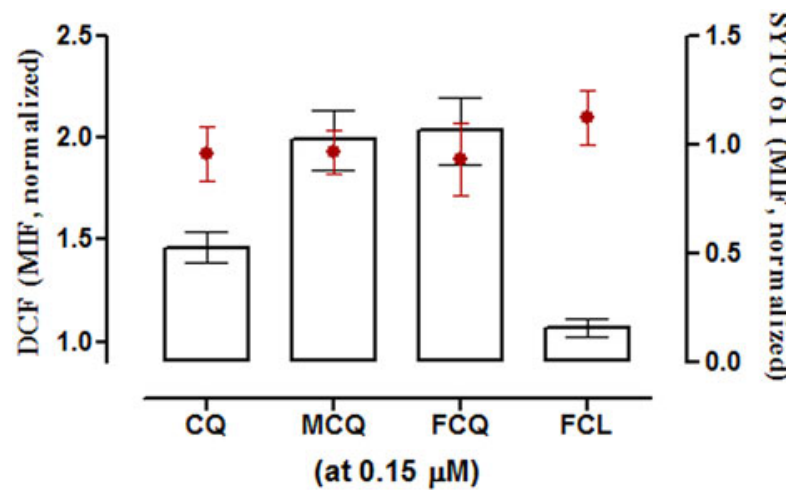

Fig. 5. 3D7 strain P. falciparum trophozoites $(3 \cdot 0 \%$ parasitaemia, $1 \%$ hematocrit) double stained with CMH2-DCFDA (probe for reactive oxygen species) and SYTO 61 (probe for cell viability). Drugs were incubated for $4 \mathrm{~h}$ and analysed by flow cytometry. Bars represent DCF signal and red dots represent SYTO 61 signal. MIF were normalized from untreated control and obtained from pooling data gathered of two independent experiments. MIF, median intensity fluorescence. Error bars represent standard deviation.

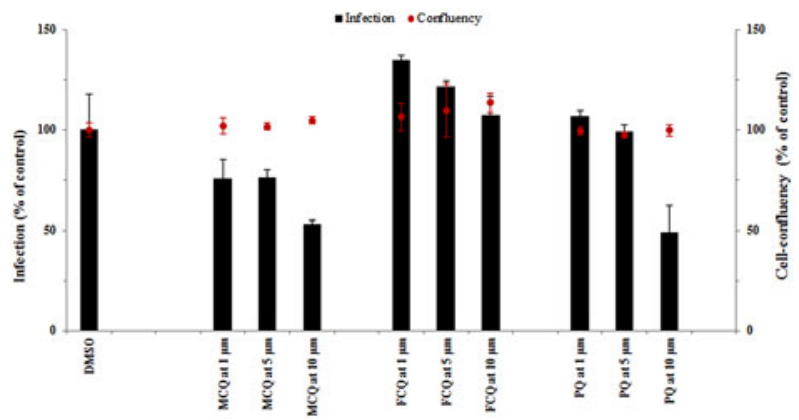

Fig. 6. Drug-susceptibility testing against $P$. berghei sporozoites. Seeded Huh7 cells were treated with drugs and infected with sporozoites. Bioluminescence intensity was measured $48 \mathrm{~h}$ post-infection. Bars represent infection and red dots represent Huh7 cell confluency. Untreated control received only DMSO. PQ, Primaquine. Error bars represent standard deviation from each concentration in triplicate. Results of two independent experiments.

at $5.0 \mathrm{mg} \mathrm{kg}^{-1}$. Due to its low SI, FFCQ was not tested in mice. By following 4-day treatment test in $P$. berghei-infected mice, parasitaemia suppression and survival rate were evaluated in comparison with untreated infected mice (vehicle). CQ was used as the reference drug (Table 5, Fig. S5). On day 8 post-infection, $50 \mathrm{mg} \mathrm{kg}^{-1}$ of $M C Q$ caused a $95.1 \%$ reduction in parasitaemia in comparison with untreated group, with $40 \%$ of animal survival observed 30 days post-infection. When $M C Q$ was used at $10 \mathrm{mg} \mathrm{kg}^{-1}$, a $46 \cdot 2 \%$ reduction in parasitaemia was observed and no survival was achieved. In infected mice treated with $F C Q$, parasitaemia was reduced by $76.9 \%$ vs untreated group. Treatment with $10 \mathrm{mg} \mathrm{kg}^{-1} B C Q$ led to a $62 \cdot 3 \%$ reduction in parasitaemia and $40 \%$ protection in
Table 4. In vitro activity of organoruthenium complexes against stage $\mathrm{V}$ gametocytes of $3 \mathrm{D} 7$ P. falciparum

\begin{tabular}{ll}
\hline \hline Compounds & $\mathrm{IC}_{50} \pm$ s.D. $(\mu \mathrm{M})^{\mathrm{a}}$ \\
\hline CQ & $>20$ \\
MCQ & $>14 \cdot 5$ \\
FCQ & $4 \cdot 28 \pm 1 \cdot 05$ \\
BCQ & $0 \cdot 78 \pm 0 \cdot 24$ \\
FFCQ & $1 \cdot 43 \pm 0 \cdot 24$ \\
Methylene blue & $0 \cdot 047 \pm 0 \cdot 015$ \\
\hline
\end{tabular}

a Activity determined in gametocytes incubated for $72 \mathrm{~h}$ with drugs. Three independents experiments performed, each concentration in duplicate.

Table 5. Summary of activities of organoruthenium complexes against blood stage in vivo infection

\begin{tabular}{llll}
\hline \hline Compounds & $\begin{array}{l}\text { Doses } \\
\left(\mathrm{mg} \mathrm{kg}^{-1}\right)^{\mathrm{a}}\end{array}$ & $\begin{array}{l}\text { \% infection } \\
\text { reduction }^{\mathrm{b}}\end{array}$ & Survival $^{\mathrm{c}}$ \\
\hline Vehicle & 0 & - & $0 / 5$ \\
$\mathrm{MCQ}$ & 50 & $95 \cdot 1$ & $2 / 5$ \\
& 10 & $46 \cdot 2$ & $0 / 5$ \\
$\mathrm{FCQ}$ & $5 \cdot 0$ & $48 \cdot 7$ & $0 / 5$ \\
$\mathrm{BCQ}$ & $5 \cdot 0$ & $76 \cdot 9$ & $0 / 5$ \\
$\mathrm{CQ}$ & 10 & $62 \cdot 3$ & $2 / 5$ \\
& 50 (oral) & 100 & $5 / 5$ \\
& 10 & 100 & $4 / 5$ \\
& $5 \cdot 0$ (oral) & $59 \cdot 6$ & $0 / 5$ \\
\hline \hline
\end{tabular}

a Given for 4 days, by intraperitoneal route, with the exception for CQ at 50 and $5.0 \mathrm{mg} \mathrm{kg}^{-1}$, which were given orally. Vehicle $=$ DMSO: saline $(20: 80 \mathrm{v} / \mathrm{v})$.

b Determined on day 8 post infection.

c Number of mice alive 30 days post infection/ $(n=5)$.

animal survival vs untreated group. In comparison, treatment with CQ at same dose reduced in $100 \%$ the parasitaemia and conferred $80 \%$ protection in animal survival.

\section{DISCUSSION}

The insertion of CQ into organoruthenium complex resulted in compounds with antiparasitic activity, while a ruthenium complex lacking CQ did not present such property. Most complexes displayed potency and selectivity against the Plasmodium blood asexual stage with a magnitude similar to that of free CQ. Unspecific cytotoxicity was only observed for the $F F C Q$ complex, possibly due to the presence of 4,7-diphenyl-1,10-phenanthroline ligand in its composition. Like CQ, complexes presented activity against all forms of blood asexual stages (rings, trophozoites and schizonts), which is an important characteristic to reduce a mixed parasite population during infection. A common feature of metal complexes is dissociation in 
solution, with concomitant ligand exchange (Peacock and Sadler, 2008). Here we showed that these organoruthenium complexes do not release CQ upon solution in the same incubation time in the pharmacological evaluation, indicating that the entire organoruthenium complex is responsible for activity.

CQ-complexes present advantages in terms of pharmacological profile. Firstly, complexes inhibited the growth of all tested $P$. falciparum strains, irrespective of their drug resistance background. Secondly, they exhibited an onset of action detectable after $18 \mathrm{~h}$ drug exposure, which is faster than what is observed for $\mathrm{CQ}$ treatment. The $\mathrm{LC}_{50}$ values for complexes fall in the same micromolar range of $\mathrm{IC}_{50}$ values, indicating that compounds act as a cytotoxic rather than as a cytostatic drug. The MPC values revealed that complexes were able to clear parasites after $18 \mathrm{~h}$ drug exposure. Although these properties were not as potent as those of the fast-acting artesunate, they were superior to those observed for CQ. These findings show that ruthenium complexes induce parasite killing and this is achieved in short time. The fast parasite killing rate displayed by these complexes is attractive, especially because this can shorten treatment time as well as prevent parasite escape.

We further observed that ruthenium complexes present activity in the liver and in the blood sexual stages. In the liver-stage Plasmodium, $M C Q$ complex displayed antiparasitic activity comparable with Primaquine and superior to $\mathrm{CQ}$. Regarding the action in the sexual stage, we observed reduction of gametocyte viability in response to ruthenium complex treatment. Therefore, unlike CQ, which is classically an effective drug during blood schizogony, the ruthenium complexes show a multistage antiplasmodial profile. In fact, the effective concentrations of ruthenium complexes against sporozoites and gametocytes stages are higher than in the blood asexual stages. However, to the best of our knowledge, this is the first time that a multistage activity profile is demonstrated for metal complexes. This is desirable since drugs targeting different stages of the parasite vertebrate life cycle can work effectively in the prevention and against the relapse of malaria.

The strong activity of the complexes against trophozoites, where hemozoin formation takes place, led us to investigate whether organoruthenium complexes inhibit $\beta$-hematin formation. Except $F F C Q$, which was inactive, other complexes inhibited polymerization of hemin into $\beta$-hematin with potency similar to CQ. In contrast, all complexes presented lower binding constant to ferriprotoporphyrin IX $(\alpha$-hematin) than CQ. These results argued that complexes are more potent in interaction with hemin rather than $\beta$-hematin, which is a finding also observed for other CQ-metal complexes (Martínez et al. 2009). CQ binds to free heme through its quinoline nitrogen, while in the CQ-ruthenium complexes this nitrogen is bound to ruthenium, indicating that these complexes interact with heme in a binding process different to $\mathrm{CQ}$.

We demonstrated that the organoruthenium treatment increased ROS levels in trophozoites, where $\beta$-hematin formation is most active. Their effects on inducing oxidative stress were more pronounced than CQ-treatment and absence under treatment with CQ-lacking complex FCL. Importantly, these properties were observed in viable parasites, which reflect a primary mechanism of action of organoruthenium complexes rather than secondary consequences of cell death. Therefore, organoruthenium complexes achieved antiparasitic activity against asexual forms because they inhibit $\beta$-hematin formation, which cause an insult in parasites since it raises toxic free heme and consequently produces oxidative stress.

$M C Q$ complex exhibited a dose-dependent effect and presented an optimal efficacy when treatment was given at $50 \mathrm{mg} \mathrm{kg}^{-1}$. This reduced blood parasitaemia and increased survival, showing that organometallic complexes are efficacious and kill parasites. A similar property was observed for $B C Q$ treatment, while the $F C Q$ complex presented narrow therapeutic window, restricting its evaluation. As a limitation, the efficacy of organoruthenium complexes is inferior to $\mathrm{CQ}$ treatment. Apart from $F F C Q$ complex, unspecific cytotoxicity was not a concern since complexes were not toxic for two different cell linages (macrophages and hepatocellular cells). Absence of hemolysis of uninfected erythrocytes and of cardiotoxicity in isolated hearts suggests low toxicity for these organoruthenium complexes. Therefore, a major challenge that remains is to optimize the efficacy of this class of compounds to enable effective reduction of parasitaemia in vivo.

\section{CONCLUSION}

We have evaluated the antimalarial activity of organoruthenium complexes containing CQ. We showed that this class of compounds is stable in mixed DMSO-aqueous media without releasing $\mathrm{CQ}$, and presented potency against blood asexual forms similar to $\mathrm{CQ}$. Organoruthenium complexes exhibited moderate activity against liver stage and potent activity against sexual stage, while $\mathrm{CQ}$ is devoid of such properties. They operate by a mechanism of action that is distinct from that of $\mathrm{CQ}$, by causing oxidative stress. Importantly, we demonstrated that organoruthenium complex treatment presented efficacy in inhibiting parasitaemia in mice, pointing out that further pharmacological investigation, as well as chemical modification are relevant to strengthen antimalarial drug development based on inorganic compounds. 


\section{SUPPLEMENTARY MATERIAL}

The supplementary material for this article can be found at http://dx.doi.org/10.1017/S0031182016001153.

\section{ACKNOWLEDGEMENTS}

We are thankful to the flow cytometry facility of CPqGM (Brazil) and AVIS Comunale Milano (Italy) for providing blood samples for gametocyte culture.

\section{FINANCIAL SUPPORT}

This research was funded by FAPESB (grant PET0042/ 2013, Brazil) to M.B.P.S, FAPESP (grant 14/10516-7, Brazil) to A.A.B. and Fundação para a Ciência e Tecnologia (grant PTDC/SAU-MIC/117060/2010 Portugal) to M.P. A.A.B. and M.B.P.S. are recipients of senior fellowships by CNPq (Brazil).

\section{TRANSPARENCY DECLARATIONS}

The authors declare no competing financial interest.

\section{CONTRIBUTING AUTHORS}

A.A.B., D.R.M.M. and M.B.P.S. initiated the project and provided guidance for experimental design and interpretation of data. T.S.M. performed in vitro and in vivo drug susceptibility studies; M.D.P. assisted with cell culture; L.C.V. and M.N. synthesized and validated drugs, performed hematin assays; M.P. and M.M. performed liver stage drug activity assays; S.D. and NB performed drug susceptibility assays in gametocytes; P.C.M.O., B.C.B. and S.G.M. performed cardiotoxicity evaluation; D.R.M.M. initiated manuscript preparation. All authors have read and approved the final manuscript.

\section{REFERENCES}

Adams, M., Li, Y., Khot, H., De Kock, C., Smith, P. J., Land, K., Chibale, K. and Smith, G. S. (2013). The synthesis and antiparasitic activity of aryl- and ferrocenyl-derived thiosemicarbazone ruthenium(II)arene complexes. Dalton Transactions 42, 4677-4685.

Adams, M., de Kock, C., Smith, P. J., Land, K. M., Liu, N., Hopper, M., Hsiao, A., Burgoyne, A. R., Stringer, T., Meyer, M., Wiesner, L., Chibale, K. and Smith, G. S. (2015). Improved antiparasitic activity by incorporation of organosilane entities into half-sandwich ruthenium(II) and rhodium(III) thiosemicarbazone complexes. Dalton Transactions 44, 2456-2468.

Barbosa, M. I., Corrêa, R.S., de Oliveira, K. M., Rodrigues, C., Ellena, J., Nascimento, O.R., Rocha, V.P., Nonato, F. R., Macedo, T. S., Barbosa-Filho, J. M., Soares, M. B. and Batista, A. A. (2014). Antiparasitic activities of novel ruthenium/lapachol complexes. Fournal of Inorganic Biochemistry 136, 33-39.

Cevenini, L., Camarda, G., Michelini, E., Siciliano, G., Calabretta, M. M., Bona, R., Kumar, T. R., Cara, A., Branchini, B. R., Fidock, D. A., Roda, A. and Alano, P. (2014). Multicolor bioluminescence boosts malaria research: quantitative dual-color assay and singlecell imaging in Plasmodium falciparum parasites. Analytical Chemistry 86, 8814-8821.

Chellan, P., Land, K. M., Shokar, A., Au, A., An, S. H., Taylor, D., Smith, P. J., Riedel, T., Dyson, P. J., Chibale, K. and Smith, G.S. (2014). Synthesis and evaluation of new polynuclear organometallic Ru
(II), $\mathrm{Rh}(\mathrm{III})$ and $\operatorname{Ir}(\mathrm{III})$ pyridyl ester complexes as in vitro antiparasitic and antitumor agents. Dalton Transactions 43, 513-526.

Clavel, C. M., Păunescu, E., Nowak-Sliwinska, P., Griffioen, A. W., Scopelliti, R. and Dyson, P. J. (2015). Modulating the anticancer activity of ruthenium(II)-arene complexes. Fournal of Medicinal Chemistry 58, 3356-3365.

Colina-Vegas, L., Villarreal, W., Navarro, M., de Oliveira, C.R., Graminha, A.E., Maia, P.I., Deflon, V.M., Ferreira, A. G., Cominetti, M. R. and Batista, A. A. (2015). Cytotoxicity of $\mathrm{Ru}(\mathrm{II})$ piano-stool complexes with chloroquine and chelating ligands against breast and lung tumor cells: interactions with DNA and BSA. Fournal of Inorganic Biochemistry 153, 150-161.

D'Alessandro, S., Silvestrini, F., Dechering, K., Corbett, Y., Parapini, S., Timmerman, M., Galastri, L., Basilico, N., Sauerwein, R., Alano, P. and Taramelli, D. (2013). A Plasmodium falciparum screening assay for anti-gametocyte drugs based on parasite lactate dehydrogenase detection. Fournal of Antimicrobial Chemotherapy 68, 2048-2058. Dubar, F., Egan, T. J., Pradines, B., Kuter, D., Ncokazi, K. K., Forge, D., Paul, J. F., Pierrot, C., Kalamou, H., Khalife, J., Buisine, E., Rogier, C., Vezin, H., Forfar, I., Slomianny, C., Trivelli, X., Kapishnikov, S., Leiserowitz, L., Dive, D. and Biot, C. (2011). The antimalarial ferroquine: role of the metal and intramolecular hydrogen bond in activity and resistance. ACS Chemical Biology 6, 275-287.

Dubar, F., Slomianny, C., Khalife, J., Dive, D., Kalamou, H., Guérardel, Y., Grellier, P. and Biot, C. (2013). The ferroquine antimalarial conundrum: redox activation and reinvasion inhibition. Angewandte Chemie International Edition in English 52, 7690-7693.

Egan, T. J., Ross, D. C. and Adams, P. A. (1994). Quinoline anti-malarial drugs inhibit spontaneous formation of beta-haematin (malaria pigment). FEBS Letters 352, 54-57.

Egan, T. J., Mavuso, W. W., Ross, D. C. and Marques, H. M. (1997) Thermodynamic factors controlling the interaction of quinoline antimalarial drugs with ferriprotoporphyrin IX. Fournal of Inorganic Biochemistry 68, 137-145.

Ekengard, E., Glans, L., Cassells, I., Fogeron, T., Govender, P., Stringer, T., Chellan, P., Lisensky, G. C., Hersh, W. H., Doverbratt, I., Lidin, S., de Kock, C., Smith, P. J., Smith, G. S. and Nordlander, E. (2015). Antimalarial activity of ruthenium(ii) and osmium(ii) arene complexes with mono- and bidentate chloroquine analogue ligands. Dalton Transactions 44, 19314-19329.

Fu, Y., Tilley, L., Kenny, S. and Klonis, N. (2010). Dual labeling with a far red probe permits analysis of growth and oxidative stress in $P$. falciparum-infected erythrocytes. Cytometry Part A. 77, 253-263.

Gabbiani, C., Messori, L., Cinellu, M.A., Casini, A., Mura, P., Sannella, A. R., Severini, C., Majori, G., Bilia, A. R. and Vincieri, F.F. (2009). Outstanding plasmodicidal properties within a small panel of metallic compounds: hints for the development of new metal-based antimalarials. Fournal of Inorganic Biochemistry 103, 310-312. Glans, L., Taylor, D., de Kock, C., Smith, P. J., Haukka, M., Moss, J. R. and Nordlander, E. (2011). Synthesis, characterization and antimalarial activity of new chromium arene-quinoline half sandwich complexes. Fournal of Inorganic Biochemistry 105, 985-990.

Glans, L., Ehnbom, A., de Kock, C., Martínez, A., Estrada, J., Smith, P. J., Haukka, M., Sánchez-Delgado, R. A. and Nordlander, E. (2012a). Ruthenium(II) arene complexes with chelating chloroquine analogue ligands: synthesis, characterization and in vitro antimalarial activity. Dalton Transactions 41, 2764-2773.

Glans, L., Hu, W., Jöst, C., de Kock, C., Smith, P. J., Haukka, M., Bruhn, H., Schatzschneider, U. and Nordlander, E. (2012b). Synthesis and biological activity of cymantrene and cyrhetrene 4-aminoquinoline conjugates against malaria, leishmaniasis, and trypanosomiasis. Dalton Transactions 41, 6443-6450.

Goldberg, D. E., Sharma, V., Oksman, A., Gluzman, I. Y., Wellems, T.E. and Piwnica-Worms, D. (1997). Probing the chloroquine resistance locus of Plasmodium falciparum with a novel class of multidentate metal(III) coordination complexes. Fournal of Biological Chemistry 272, 6567-6572.

Huta, B. P., Mehlenbacher, M. R., Nie, Y., Lai, X., Zubieta, C., BouAbdallah, F. and Doyle, R. P. (2016). The lysosomal protein saposin B binds chloroquine. ChemMedChem 11, 277-282.

Khanye, S. D., Smith, G.S., Lategan, C., Smith, P.J., Gut, J, Rosenthal, P. J. and Chibale, K. (2010). Synthesis and in vitro evaluation of gold(I) thiosemicarbazone complexes for antimalarial activity. Fournal of Inorganic Biochemistry 104, 1079-1083.

Lewis, M. D., Behrends, J., Sá, E., Cunha, C., Mendes, A. M., Lasitschka, F., Sattler, J. M., Heiss, K., Kooij, T. W., Navarro, M., Pérez, H. and Sánchez-Delgado, R. A. (1997). Toward a novel 
metal-based chemotherapy against tropical diseases. 3. Synthesis and antimalarial activity in vitro and in vivo of the new gold-chloroquine complex $[\mathrm{Au}(\mathrm{PPh} 3)(\mathrm{CQ})] \mathrm{PF} 6$. Fournal of Medicinal Chemistry 40 1937-1939.

Lin, J. W., Spaccapelo, R., Schwarzer, E., Sajid, M., Annoura, T. Deroost, K., Ravelli, R. B., Aime, E., Capuccini, B., MommaasKienhuis, A.M., O'Toole, T., Prins, F., Franke-Fayard, B. M., Ramesar, J., Chevalley-Maurel, S., Kroeze, H., Koster, A. J., Tanke, H. J., Crisanti, A., Langhorne, J., Arese, P., Van den Steen, P.E., Janse, C. J. and Khan, S. M. (2015). Replication of Plasmodium in reticulocytes can occur without hemozoin formation, resulting in chloroquine resistance. Fournal of Experimental Medicine 212, 893-903.

Martínez, A., Rajapakse, C.S., Jalloh, D., Dautriche, C. and Sánchez-Delgado, R. A. (2009). The antimalarial activity of Ru-chloroquine complexes against resistant Plasmodium falciparum is related to lipophilicity, basicity, and heme aggregation inhibition ability near water/n-octanol interfaces. Fournal of Biological Inorganic Chemistry 14, 863-871.

Martínez, A., Suárez, J., Shand, T., Magliozzo, R.S. and SánchezDelgado, R. A. (2011). Interactions of arene-Ru(II)-chloroquine complexes of known antimalarial and antitumor activity with human serum albumin (HSA) and transferrin. Fournal of Inorganic Biochemistry 105, 39-45.

Maschke, M., Alborzinia, H., Lieb, M., Wölfl, S. and MetzlerNolte, N. (2014). Structure-activity relationship of trifluoromethylcontaining metallocenes: electrochemistry, lipophilicity, cytotoxicity, and ROS production. ChemMedChem 9, 1188-1194.

Meier, S. M., Novak, M., Kandioller, W., Jakupec, M. A., Arion, V. B., Metzler-Nolte, N., Keppler, B. K. and Hartinger, C. G. (2013) Identification of the structural determinants for anticancer activity of a ruthenium arene peptide conjugate. Chemistry 19, 9297-9307.

Navarro, M., Vásquez, F., Sánchez-Delgado, R. A., Pérez, H., Sinou, V. and Schrével, J. (2004). Toward a novel metal-based chemotherapy against tropical diseases. 7 . Synthesis and in vitro antimalaria activity of new gold-chloroquine complexes. Fournal of Medicinal Chemistry 47, 5204-209.

Navarro, M., Castro, W., Higuera-Padilla, A. R., Sierraalta, A. Abad, M. J., Taylor, P. and Sánchez-Delgado, R. A. (2011a) Synthesis, characterization and biological activity of trans-platinum(II) complexes with chloroquine. Fournal of Inorganic Biochemistry 105 1684-1691

Navarro, M., Castro, W., Martínez, A. and Sánchez Delgado, R. A $(2011 b)$. The mechanism of antimalarial action of $[\mathrm{Au}(\mathrm{CQ})(\mathrm{PPh}(3))]$ $\mathrm{PF}(6)$ : structural effects and increased drug lipophilicity enhance heme aggregation inhibition at lipid/water interfaces. Fournal of Inorganic Biochemistry 105, 276-282.

Navarro, M., Castro, W., Madamet, M., Amalvict, R., Benoit, N. and Pradines, B. (2014). Metal-chloroquine derivatives as possible anti-malarial drugs: evaluation of anti-malarial activity and mode of action. Malaria Fournal 13, 471

Nilsson, S. K., Childs, L. M., Buckee, C. and Marti, M. (2015) Targeting human transmission biology for malaria elimination. PLoS Pathogens 11, e1004871.

Parapini, S., Basilico, N., Pasini, E., Egan, T. J., Olliaro, P. Taramelli, D. and Monti, D. (2000). Standardization of the physicochemical parameters to assess in vitro the beta-hematin inhibitory activity of antimalarial drugs. Experimental Parasitology 96, 249-256.
Peacock, A. F. and Sadler, P. J. (2008). Medicinal organometallic chemistry: designing metal arene complexes as anticancer agents. Chemistry Asian fournal 3, 1890-1189.

Pérez, B. C., Teixeira, C., Albuquerque, I. S., Gut, J., Rosenthal, P. J., Gomes, J. R., Prudêncio, M. and Gomes, P. (2013). N-cinnamoylated chloroquine analogues as dual-stage antimalarial leads. Fournal of Medicinal Chemistry 56, 556-567.

Petersen, I., Eastman, R. and Lanzer, M. (2011). Drug-resistant malaria: molecular mechanisms and implications for public health. FEBS Letters 585, 1551-1562.

Ploemen, I. H., Prudêncio, M., Douradinha, B. G., Ramesar, J., Fonager, J., van Gemert, G. J., Luty, A. J., Hermsen, C. C., Sauerwein, R. W., Baptista, F. G., Mota, M. M., Waters, A.P. Que, I., Lowik, C. W., Khan, S. M., Janse, C. J. and FrankeFayard, B. M. (2009). Visualisation and quantitative analysis of the rodent malaria liver stage by real time imaging. Plos ONE 4, e7881.

Price, R. N., von Seidlein, L., Valecha, N., Nosten, F., Baird, J. K. and White, N. J. (2014). Global extent of chloroquine-resistant Plasmodium vivax: a systematic review and meta-analysis. Lancet Infectious Diseases 14, 982-991.

Prudêncio, M., Rodriguez, A. and Mota, M. M. (2006). The silent path to thousands of merozoites: the Plasmodium liver stage. Nature Reviews Microbiology 4, 849-856.

Prudêncio, M., Mota, M. M. and Mendes, A. M. (2011). A toolbox to study liver stage malaria. Trends in Parasitology 27, 565-574.

Prudêncio, M., Bringmann, G., Frischknecht, F. and Mueller, A. K. (2015). Chemical attenuation of Plasmodium in the liver modulates severe malaria disease progression. Fournal of Immunology. 194, 4860-4870.

Rajapakse, C.S., Martínez, A., Naoulou, B., Jarzecki, A. A. Suárez, L., Deregnaucourt, C., Sinou, V., Schrével, J., Musi, E., Ambrosini, G., Schwartz, G. K. and Sánchez-Delgado, R. A. (2009) Synthesis, characterization, and in vitro antimalarial and antitumor activity of new ruthenium(II) complexes of chloroquine. Inorganic Chemistry 48 , $1122-1131$

Rodrigues, T., Prudêncio, M., Moreira, R., Mota, M. M. and Lopes, L. (2012). Targeting the liver stage of malaria parasites: a yet unmet goal. Fournal of Medicinal Chemistry 55, 995-1012.

Salas, P.F., Herrmann, C., Cawthray, J.F., Nimphius, C. Kenkel, A., Chen, J., de Kock, C., Smith, P. J., Patrick, B. O., Adam, M. J. and Orvig, C. (2013). Structural characteristics of chloroquine-bridged ferrocenophane analogues of ferroquine may obviate malaria drug-resistance mechanisms. Fournal of Medicinal Chemistry 56 $1596-1613$.

Sánchez-Delgado, R. A., Navarro, M., Pérez, H. and Urbina, J. A. (1996). Toward a novel metal-based chemotherapy against tropical diseases. 2. Synthesis and antimalarial activity in vitro and in vivo of new ruthenium- and rhodium-chloroquine complexes. Fournal of Medicinal Chemistry 39, 1095-1099.

Scovill, J.P., Klayman, D. L. and Franchino, C. F. (1982), 2 Acetylpyridine thiosemicarbazones. 4. Complexes with transition metals as antimalarial and antileukemic agents. Fournal of Medicinal Chemistry 25, 1261-1264

Stone, W., Gonçalves, B.P., Bousema, T. and Drakeley, C. (2015) Assessing the infectious reservoir of falciparum malaria: past and future. Trends in Parasitology 31, 287-296.

WHO Global Malaria Programme. World Malaria Report (2015), World Health Organization, Geneva, 2015. http://apps.who.int/iris/ bitstream/10665/200018/1/9789241565158_eng.pdf?ua=1 